\title{
Direct application of plasmid DNA containing type I interferon transgenes to vaginal mucosa inhibits HSV-2 mediated mortality
}

\author{
Bobbie Ann Austin¹, Cassandra M. James², Peter Härle³ and Daniel J.J. Carr1,4* \\ 1Department of Ophthalmology, University of Oklahoma Health Sciences Center, Oklahoma City, OK, USA. \\ ${ }^{2}$ Division of Veterinary \& Biomedical Health Science, Murdoch University, Perth, Australia 6150. \\ ${ }^{3}$ Laboratory of Neuroendocrinoimmunology, University Medical Center, Regensburg, Germany 93053. \\ ${ }^{4}$ Departments of Ophthalmology and Microbiology and Immunology, University of Oklahoma Health Sciences Center, Oklahoma City, OK, USA. \\ *Corresponding Author: Daniel J.J. Carr, Departments of Ophthalmology and Microbiology and Immunology, University of Oklahoma Health Sciences \\ Center, Oklahoma City, OK, USA. Email: dan-carr@ouhsc.edu
}

Submitted: November 14, 2005; Revised: May 17, 2006; Accepted: May 17, 2006.

Indexing terms: Virus; Interferon; T-lymphocyte; Transgene.

\begin{abstract}
The application of naked DNA containing type I interferon (IFN) transgenes is a promising potential therapeutic approach for controlling chronic viral infections. Herein, we detail the application of this approach that has been extensively used to restrain ocular HSV-1 infection, for antagonizing vaginal HSV-2 infection. We show that application of IFN- $\alpha 1,-\alpha 5$, and $-\beta$ transgenes to vaginal mouse lumen 24 hours prior to HSV-2 infection reduces HSV2 mediated mortality by 2.5 to 3 -fold. However, other type I IFN transgenes (IFN- $\alpha 4,-\alpha 5,-\alpha 6$, and $-\alpha 9$ ) are non effectual against HSV-2. We further show that the efficacy of IFN- $\alpha 1$ transgene treatment is independent of CD4+ T lymphocytes. However, in mice depleted of CD8+ T lymphocytes, the ability of IFN- $\alpha 1$ transgene treatment to antagonize HSV-2 was lost.
\end{abstract}

\section{INTRODUCTION}

Herpes simplex virus 2 (HSV-2) is a sexually transmitted disease that causes painful recurrent mucosal cutaneous ulcerations. The overall estimated seroprevalence among humans living in the United States is $21.9 \%$ (1). Being a disease process with a disparate distribution in populations, HSV-2 affects even a higher percentage of humans of female gender, low socioeconomic status, and African or Mexican heritage $(1,2)$. Other risk factors for HSV-2 infection include: use of contraceptives in women $(3,4)$, minimal education, and number of sexual patterns (5). The development of genital ulcerations also augments the risk of human immunodeficiency virus (HIV) transmission (6); reciprocally, the infectiousness of $\mathrm{HIV}$ also increases during periods of $\mathrm{HSV}-2$ reactivation (6).
Like other herpes viruses humans are the predominate host for HSV-2, and the virus establishes a lifelong infection. HSV-2 spreads from one human host to another via transmission of infectious virus in mucosal secretions at epithelial surfaces. Virus initially replicates within epithelial tissue in the initial site of inoculation prior to entering associated sensory ganglia, such as the sacral ganglia. Within sensory ganglia neurons, HSV-2 establishes a latent infection, from which the virus periodically reactivates and re-infects the initial site of infection. Episodic reactivations transpire as many as 4-5 times per year. However, recrudescent viral shedding is also common (7-9).

While HSV-2 is most commonly coupled with urogenital tract lesions, the virus can also inoculate mucosal epithelium in the upper body and establish latent 
infection in associated sensory neurons. A number of ocular diseases originate from HSV-2 infection including: anterior uveitis, stromal keratitis, and retinal necrosis $(10,11)$. HSV-2 can further spread from sensory ganglia to the CNS causing potentially lethal meningitis and encephalitis (12). Substantial increases in the incidence of HSV-2 infections in recent years have prompted studies to develop vaccinations and anti-viral therapies to curb this epidemic $(13,14)$.

Naked DNA vaccines encoding viral antigens or immune system adjuvants, such as chemokines have been tested as experimental vaccines against herpes simplex viruses 1 and 2 (15-21) and other viruses. A number of advantages with DNA vaccination have been enumerated including: relatively inexpensive vaccine preparation and resistance to temperatures over $50^{\circ} \mathrm{C}$, both of which are critical factors for vaccination in resource poor populations, where up to $69 \%$ of women have serological evidence of HSV-2 (22). To better understand mechanisms of endogenous anti-herpes pathways, our lab utilizes plasmid DNA encoding type I interferon (IFN) transgenes as a means to control virus replication and spread.

IFNs are endogenous anti-viral cytokines elicited in response to viral infection. Transfection of mice with type I IFN transgenes is an established approach to reduce HSV-1 mediated mortality (23). Furthermore, the ability of type I IFN transgenes to antagonize HSV-1 relies on OAS/RNase L pathway induction (23), a known downstream IFN effector, which inhibits viral infectivity via RNA degradation. Transfection of mice with IFN- $\alpha 1$ transgenes also enhances cumulative survival of mice vaginally infected with HSV-2 (24). However, the facility of IFN- $\alpha 1$ transgene treatment to antagonize HSV-2 does not require induction of the OAS/RNase L pathway. Conversely, the ability of IFN- $\alpha 1$ transgene to antagonize HSV-2 requires induction of protein kinase $R$, an IFN inducible anti-viral pathway that inhibits protein synthesis (25). Presently, we detail the methodology for utilizing type I IFN transgenes to manage vaginal HSV-2 infection in a mouse model. We further show that the effectiveness of IFN- $\alpha 1$ transgenes requires CD8+ T lymphocytes. Finally, we assess the significance of other type I IFN trangenes at preventing HSV-2 mediated mortality.

\section{MATERIALS AND METHODS}

\section{Treatment of mice}

Animal treatment was consistent with the National Institutes of Health Guidelines on the Care and Use of Laboratory Animals. All procedures were approved by the University of Oklahoma Health Sciences Center and Dean A McGee Eye Institutional Animal Care and Use Committees. Female ICR mice (Sprague Dawley, from Harlan Sprague Dawley), ages 6-8 weeks were subcutaneously injected with $2 \mathrm{mg}$ DepoProvera $5 \mathrm{~d}$ prior to infection, since progesterone facilitates vaginal HSV-2 infection $(26,27)$. Four days after administration of DepoProvera, mice were anesthetized by i.p. injection with xylazine $(2 \mathrm{mg} / \mathrm{ml} ; 6.6 \mathrm{ml} / \mathrm{kg})$ and ketamine $(30$ $\mathrm{mg} / \mathrm{ml} ; 100 \mathrm{mg} / \mathrm{kg}$ ). Subsequently, vaginal mucous was removed with sterile calcium alginate fiber tipped swabs (Fisher Scientific) prior to vaginal transfection with IFN transgenes - local administration of $100 \mu \mathrm{g}$ DNA in $20 \mu \mathrm{l}$ TE buffer - $10 \mathrm{mM}$ Tris, $1 \mathrm{mM}$ ethylendiaminetetracetic acid (EDTA), $\mathrm{pH}$ 8.0. Five days after administration of DepoProvera, mice were anesthetized (as described previously) and vaginal mucous was again removed prior to infecting vaginal lumen with 2,400 plaque forming units (PFU) HSV-2. Mice were monitored over $30 \mathrm{~d}$ post-infection (p.i.), and mortality was recorded for each group of animals.

\section{Virus and cells}

All culture media reagents were from Life Technologies, Gaithersburg, MD. Vero cells (African green monkey kidney), obtained from the American Type Culture Collection (Manassas, VA) were cultured in RPMI 1640, supplemented with 5\% FBS, $2 \%$ antibiotic/antimycotic, and $0.2 \%$ gentamicin. Cells cultures were incubated in an atmosphere of $37^{\circ} \mathrm{C}, 5 \% \mathrm{CO}_{2}$, and $95 \%$ humidity.

A clinical isolate of HSV-2 was obtained from University Hospital (New Orleans, LA) and propagated on Vero cells (28). Specifically, confluent monolayers of Vero cells, grown in two T-175 culture flasks, were infected with 0.1 MOI HSV-2, diluted in $6 \mathrm{mls}$ prepared RPMI media. After 1 hour, medium was replaced with $20 \mathrm{ml}$ fresh complete medium. When $90 \%$ cytopathic effect was observed, cells were subjected to one freeze thaw cycle. 
Cells were collected and non viral cellular debris was pelleted away from virus by centrifugation for 15 minutes at 4,000 rpm. Supernatant was further clarified by one more centrifugation for 15 minutes at 4,000 rpm. HSV-2 was pelleted from the clarified supernatant by centrifugation at 20,000 g $\times 2 \mathrm{~h}$. Viral pellets were washed two times with sterile $1 \mathrm{x}$ phosphate buffered saline (PBS) and viral suspensions were combined in 1 $\mathrm{ml}$ sterile $1 \mathrm{x}$ PBS. Aliquots $(50 \mu \mathrm{l})$ were stored at $-80^{\circ} \mathrm{C}$. Viral titer in triplicate was determined by transferring logarithmic dilutions $\left(10^{-5}\right.$ to $\left.10^{-9}\right)$ of HSV-2, diluted in complete medium, onto confluent Vero cells in 24-well plates. After 1 hour, medium was replaced with $0.5 \%$ methylcellulose, diluted in complete medium. Viral plaque formation was assessed after a $32 \mathrm{~h}$ incubation period and recorded as $\mathrm{PFU} / \mathrm{ml}$.

\section{CD4+ and CD8+ T cell depletion}

CD4+ and CD8+ T lymphocytes were depleted and the depletion of T lymphocyte populations was monitored as previously described (29).

\section{Plasmid DNA construction}

The plasmid backbone, pkCMV (vector) was obtained from Vical Inc., San Diego, CA. This vector consists of: a) plasmid double stranded DNA backbone, b) immediate early CMV promoter for expression in mammalian cells, c) intron with splice donor/splice acceptor where the murine IFN transgenes (575-626 bp) were inserted (30), d) ori sequence for replication in mammalian cells, e) SV40 polyadenlyation signal, f) pUC origin of replication for propagation in Escherichia coli g) kanamycin resistance gene for selection in E. Coli. Further details about the original source and cloning procedures (30-34) have been described. Plasmid constructs were transformed into E. coli strain INV $\alpha \mathrm{F}^{\prime}$ (Invitrogen, Carlsbad, CA) and products were analyzed by agarose gel electrophoresis (30). More details about plasmid production and purification can be found in the protocols section.

\section{Statistical analysis}

Survival studies were analyzed for significance $(\mathrm{p} \leq 0.05)$ by the Mann-Whitney $U$ rank sum test, using the GBSTAT program (Dynamic Microsystems, Gaithersburg, MD).

\section{RESULTS}

In ICR mice, which are highly susceptible to the lethal effects of herpes (35), we previously showed that transfection of mouse corneas with IFN- $\alpha 1$ and $-\beta$ transgenes, 24 hours prior to HSV-1 infection, enhanced the cumulative survival of mice by 3 -fold (23). Other type I IFN transgene treatments (IFN- $\alpha 5$ and $-\alpha 6$ ) were not effective at preventing the lethal effects of HSV-1 infection (23). To further explore whether type I IFN transgene subtypes also provide diverse levels of protection against HSV-2 infection, survival studies with type I IFN transgene treatment of female ICR mice, vaginally infected with HSV-2 were initiated. The cumulative survival of mice treated with IFN- $\alpha 1,-\alpha 5$, and $-\beta$ transgenes, 24 hours prior to vaginal HSV-2 infection was enhanced by 2.5 to 3 -fold (Fig. 1) in comparison to mice treated with vector alone (plasmid DNA backbone without an IFN transgene). Other IFN transgenes (IFN- $\alpha 4,-\alpha 6$, and $-\alpha 9$ ) were not effective at reducing HSV-2 mediated mortality (Fig. 1).

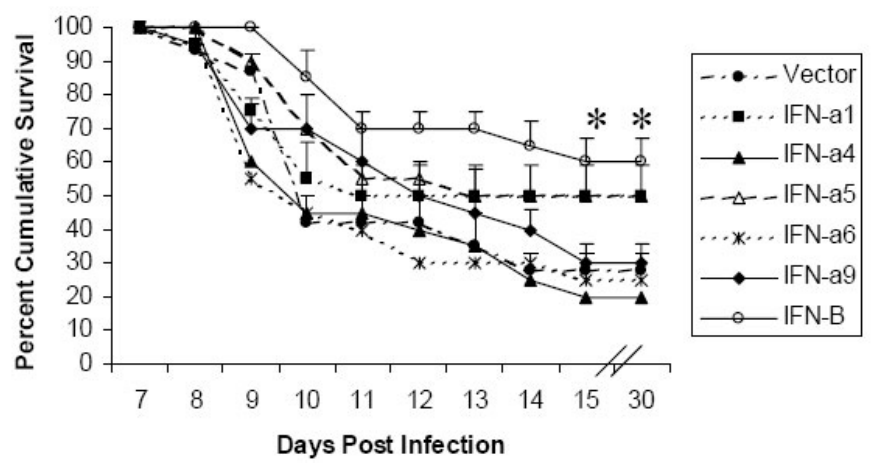

Fig. 1: A comparison of cumulative survival of mice when treated with IFN$\alpha 1,-\alpha 5$, and $-\beta$ transgenes and with vector alone.

Previously, we showed that CD4+ and CD8+ T lymphocytes are required for the anti-HSV-1 activity of IFN- $\alpha 1$ transgene treatment (29). To determine whether both CD4+ and CD8+ T lymphocytes are also required for the anti-HSV-2 activity of IFN- $\alpha 1$ transgene treatment, CD4+ and CD8+ T lymphocytes were depleted in mice hormonally susceptible to HSV-2. In comparison to treatment with normal rat serum, the cumulative survival of HSV-2 infected mice decreased by 2 and 4fold, respectively, following depletion of CD8+ and CD4+ T lymphocytes (Fig. 2A). While the absence of both types of $\mathrm{T}$ lymphocytes negatively affected the survival of HSV-2 infected mice, with IFN- $\alpha 1$ transgene treatment, the impact of CD4+ $\mathrm{T}$ lymphocyte depletion was 
reversible. Specifically, mortality rates at the end of $30 \mathrm{~d}$ with IFN- $\alpha 1$ transgene treatment in CD4+ T lymphocyte depleted mice as well as mice treated with normal rat serum were the same (Fig. 2B). In contrast to this observation, in mice depleted of CD8+ T lymphocytes, the effectiveness of IFN- $\alpha 1$ transgene treatment was lost. With IFN- $\alpha 1$ transgene treatment and CD8+ $\mathrm{T}$ lymphocyte depletion, survival following HSV-2 infection decreased 2-fold, in comparison to survival with IFN- $\alpha 1$ transgene treatment in mice treated with normal rat serum (Fig. 2B).
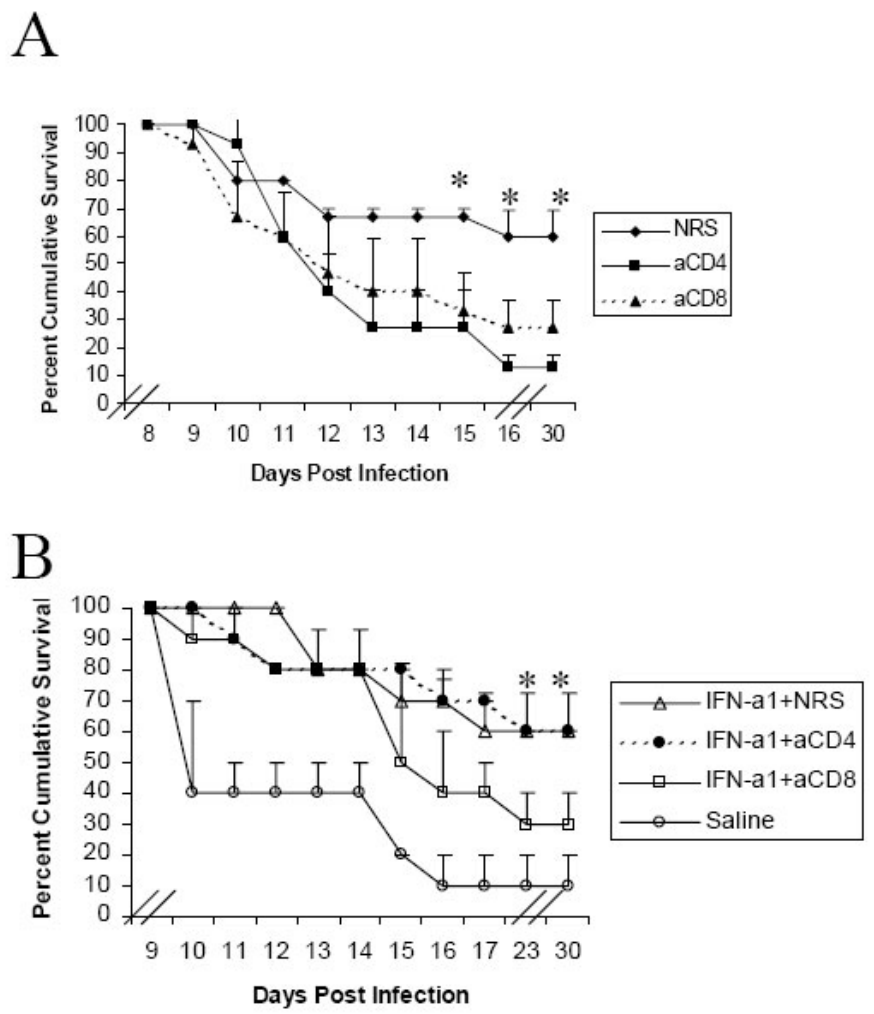

Fig. 2: The treatment of HSV-2 infected mice and cumulative survival and the impact of CD4+ T-lymphocyte depletion.

\section{DISCUSSION}

Previous work from our lab has shown that IFN transgene treatment is effective at reducing herpes mediated mortality, inhibiting viral replication, reducing viral antigen expression, reducing viral protein synthesis, reducing inflammatory leukocyte infiltration, inducing interferon stimulated gene expression, and inhibiting herpes reactivation $(23,24,30,36-41)$. In applying this methodology to antagonize other viruses, it is noteworthy that we have found application of transgenes 24 hours before HSV-1 infection to be more effective than earlier time points before infection or transgene treatment post-infection $(29,37,38)$, with a minimal effective dose of 50-100 $\mu \mathrm{g}$ DNA/mouse eye (HSV-1) or $100 \mu \mathrm{g}$ DNA/mouse vagina (HSV-2). The usefulness of transgene treatment, with respect to time of infection, is likely related to the transient nature of transgene expression following transfection. With IFN- $\alpha 1$ transgene treatment, transgene expression is only detected 24-72 hours post-transfection (37). The shortterm nature of transgene expression following transfection using a naked DNA approach is a known obstacle to DNA based vaccine strategies (42). Transgene inoculation intramuscularly provides longer term expression (43).

In addition to length of expression, efficiency of transfection is also challenging. Following plasmid DNA transfection, only a small fraction of DNA molecules actually transfect target cells (42). Thus, high plasmid doses are typically used in animal models $(42,44)$. In our system we have shown, using a LacZ reporter gene, evidence of gene expression in vaginal epithelium at 3 days following application of plasmid DNA (24). The plasmid DNA also trafficks to the spinal cord and lymphatic tissue, 24 hours post-transfection of HSV-2 infected tissue (24). Coupled with the efficiency of transfection, we have encountered difficulties measuring biologically active levels of IFN following transfection of vaginal epithelium. However, we are able to detect increased levels of interferon stimulated gene expression using real time PCR (25). Ongoing efforts to overcome obstacles related to length and efficiency of transfection include: improving transfection efficiency and protecting DNA from degradation (42).

Transient expression is considered advantageous in the respect that foreign DNA is less likely to insert into the host genome (45). Even so, it is a critical consideration to develop delivery systems that target gene delivery to appropriate tissues. Delivery of IFN-transgenes via a mucosal route is a useful approach to study immune response because mucosal surfaces are the most likely site for herpes to invade hosts, and application of plasmid DNA is known to induce local and systemic cellular and humoral immunity (45). Related to this, it is vital to use a vector (control) in each experiment to separate IFN-inducible effects from immune response elicited by CpG motifs in the plasmid DNA backbone. In 
our model following topical application of plasmid DNA to vagina, reporter gene expression is detected locally and also in lymph node and spinal cord (24). Likewise, following topical application of plasmid DNA to eye, reporter gene expression is detected locally, with the innervating sensory ganglia (i.e., trigeminal ganglia), and also in spleen (29). Stimulation of humoral and cellular immunity with plasmid DNA is considerably less harmful than utilizing attenuated virus (46), and the adjuvant effect of CPG DNA is considered beneficial for immune studies because a separate adjuvant is not required. Nevertheless, identification of critical sites of targeted delivery along with increased delivery efficiency would enable the smallest effective dose. Smaller doses targeted to specific cells both reduce random distribution of foreign genes and increase therapeutic cost effectiveness.

Attempts to control delivery of plasmid DNA include use of polymers that condense plasmid DNA and increase diffusion through plasmid membrane, and use of cell-specific targeting ligands (47). Cell-specific targeting has been achieved by conjugating peptide to proteins that function to condense plasmid DNA. Moreover, conjugation of certain antibodies to lipids has been shown to increase efficiency of cell uptake. For example, conjugation of anti-transferrin antibodies to liposome-DNA complexes has been shown to increase gene delivery to cornea (48). Conjugation of transferrin to polyethyleneimine has further been shown to enhance transfection efficiency, likely via enhanced endocytosis (48).

Other attempts to control transgene expression involve development of tissue and cell-specific expression systems. Our IFN transgenes are under the control of a promiscuous viral promoter, CMV. This factor combined with distribution of plasmid DNA both locally as well as to lymphatic system, potentially leads to more widespread distribution of IFN than required for controlling site-specific herpes pathogenesis. Systemic release of high levels of IFN is known to cause numerous unwanted side effects including: fever, chills, headaches, achy muscles, diarrhea, loss of appetite, anemia, increased bleeding and bruising, and birth defects. Development of a more site-specific IFN-based anti-viral therapy with controlled expression is a long term goal. Generally, non-viral based transfection agents are not effective for delivering genes to the nervous system. Use of replication defective herpes amplicons or other replication defective neurotropic viruses show promise as potential vectors for delivery of anti-viral genes specifically to sites of herpes infection.

\section{ACKNOWLEDGMENTS}

This work was supported by USPHS grant AI053108 (DJJC) and additional support from an NEI core grant EY12190. The authors have no conflicts of interest to declare related to this publication.

\section{REFERENCES}

1. Fleming DT, McQuillan GM, Johnson RE, Nahmias AJ, Aral SO, Lee FK, et al. Herpes simplex virus type 2 in the United States, 1976 to 1994. N Engl J Med 1997; 337(16):1105-1111.

2. Sacks SL, Griffiths PD, Corey L, Cohen C, Cunningham A, Dusheiko GM, et al. HSV-2 transmission. Antiviral Res 2004; 63 Suppl 1:S27-S35.

3. Cherpes TL, Melan MA, Kant JA, Cosentino LA, Meyn LA, Hillier SL. Genital tract shedding of herpes simplex virus type 2 in women: effects of hormonal contraception, bacterial vaginosis, and vaginal group B Streptococcus colonization. Clin Infect Dis 2005; 40(10):1422-1428.

4. Mostad SB, Kreiss JK, Ryncarz AJ, Mandaliya K, Chohan B, Ndinya-Achola J, et al. Cervical shedding of herpes simplex virus in human immunodeficiency virus-infected women: effects of hormonal contraception, pregnancy, and vitamin A deficiency. J Infect Dis 2000; 181(1):58-63.

5. Wald A. Herpes simplex virus type 2 transmission: risk factors and virus shedding. Herpes 2004; 11 Suppl 3:130A-137A.

6. Celum C, Levine R, Weaver M, Wald A. Genital herpes and human immunodeficiency virus: double trouble. Bull World Health Organ 2004; 82(6):447-453.

7. Wolff MH, Schmitt J, Rahaus M, Dudda H, Hatzmann W. Clinical and subclinical reactivation of genital herpes virus. Intervirology 2002; 45(1):20-23.

8. Raguin G, Malkin JE. Genital herpes: epidemiology and pathophysiology. Update and new perspectives. Ann Med Interne (Paris) 1997; 148(8):530-533.

9. Liu V, Bigby M. Reactivation of genital herpes simplex virus 2 infection in asymptomatic 
seropositive persons is frequent. Arch Dermatol 2000; 136(9):1141-1142.

10. Tran TH, Stanescu D, Caspers-Velu L, Rozenberg F, Liesnard C, Gaudric A, et al. Clinical characteristics of acute HSV-2 retinal necrosis. Am J Ophthalmol 2004; 137(5):872-879.

11. Inoda S, Wakakura M, Hirata J, Nakazato N, ToyoOka Y. Stromal keratitis and anterior uveitis due to herpes simplex virus-2 in a young child. Jpn J Ophthalmol 2001; 45(6):618-621.

12. Kleinschmidt-DeMasters BK, Gilden DH. The expanding spectrum of herpesvirus infections of the nervous system. Brain Pathol 2001; 11(4):440-451.

13. Corey L. The current trend in genital herpes. Progress in prevention. Sex Transm Dis 1994; 21(2 Suppl):S38-S44.

14. Corey L, Langenberg AG, Ashley R, Sekulovich RE, Izu AE, Douglas JM Jr., et al. Recombinant glycoprotein vaccine for the prevention of genital HSV-2 infection: two randomized controlled trials. Chiron HSV Vaccine Study Group. Jama 1999; 282(4):331-340.

15. Rajcani J, Mosko T, Rezuchova I. Current developments in viral DNA vaccines: shall they solve the unsolved? Rev Med Virol 2005; 15(5):303325.

16. Rouse BT, Nair S, Rouse RJ, Yu Z, Kuklin N, Karem $\mathrm{K}$, et al. DNA vaccines and immunity to herpes simplex virus. Curr Top Microbiol Immunol 1998; 226:69-78.

17. Stanberry LR, Cunningham AL, Mindel A, Scott LL, Spruance SL, Aoki FY, et al. Prospects for control of herpes simplex virus disease through immunization. Clin Infect Dis 2000; 30(3):549-566.

18. McClements WL, Armstrong ME, Keys RD, Liu MA. The prophylactic effect of immunization with DNA encoding herpes simplex virus glycoproteins on HSV-induced disease in guinea pigs. Vaccine 1997; 15(8):857-860.

19. Lee HH, Cha SC, Jang DJ, Lee JK, Choo DW, Kim YS, et al. Immunization with combined HSV-2 glycoproteins B2: D2 gene DNAs: protection against lethal intravaginal challenges in mice. Virus Genes 2002; 25(2):179-188.

20. Nass PH, Elkins KL, Weir JP. Protective immunity against herpes simplex virus generated by DNA vaccination compared to natural infection. Vaccine 2001; 19(11-12):1538-1546.
21. Lee S, Gierynska M, Eo SK, Kuklin N, Rouse BT. Influence of DNA encoding cytokines on systemic and mucosal immunity following genetic vaccination against herpes simplex virus. Microbes Infect 2003; 5(7):571-578.

22. Emonyi IW, Gray RH, Zenilman J, Schmidt K, Wawer MJ, Sewankambo KN, et al. Sero-prevalence of Herpes simplex virus type 2 (HSV-2) in Rakai district, Uganda. East Afr Med J 2000; 77(8):428-430.

23. Austin BA, James C, Silverman RH, Carr DJ. Critical role for the oligoadenylate synthetase/RNase L pathway in response to IFN-beta during acute ocular herpes simplex virus type 1 infection. J Immunol 2005; 175(2):1100-1106.

24. Harle P, Noisakran S, Carr DJ. The application of a plasmid DNA encoding IFN-alpha 1 postinfection enhances cumulative survival of herpes simplex virus type 2 vaginally infected mice. J Immunol 2001; 166(3):1803-1812.

25. Carr DJ, Tomanek L, Silverman RH, Campbell IL, Williams BR. RNA-dependent protein kinase is required for alpha-1 interferon transgene-induced resistance to genital herpes simplex virus type 2. J Virol 2005; 79(14):9341-9345.

26. Baker DA, Plotkin SA. Enhancement of vaginal infection in mice by herpes simmplex virus type II with progesterone. Proc Soc Exp Biol Med 1978; 158:131-134.

27. Parr MB, Kepple L, McDermott MR, Drew MD, Bozzola JJ, Parr EL. A mouse model for studies of mucosal immunity to vaginal infection by herpes simplex virus type 2. Lab Invest 1994; 70(3):369-380.

28. Harland J, Brown SM. HSV growth, preparation, and assay. Totowa, NJ: Humana Press; 1998.

29. Noisakran S, Carr DJ. Plasmid DNA encoding IFNalpha 1 antagonizes herpes simplex virus type 1 ocular infection through $\mathrm{CD} 4+$ and $\mathrm{CD} 8+\mathrm{T}$ lymphocytes. J Immunol 2000; 164(12):6435-6443.

30. Harle P, Cull V, Guo L, Papin J, Lawson C, Carr DJ. Transient transfection of mouse fibroblasts with type I interferon transgenes provides various degrees of protection against herpes simplex virus infection. Antiviral Res 2002; 56(1):39-49.

31. Kelley KA, Pitha PM. Characterization of a mouse interferon gene locus I. Isolation of a cluster of four alpha interferon genes. Nucleic Acids Res 1985; 13(3):805-823. 
32. Seif I, De Maeyer-Guignard J. Structure and expression of a new murine interferon-alpha gene: MuIFN-alpha I9. Gene 1986; 43(1-2):111-121.

33. Lawson CM, Yeow WS, Lee CM, Beilharz MW. In vivo expression of an interferon-alpha gene by intramuscular injection of naked DNA. J Interferon Cytokine Res 1997; 17(5):255-261.

34. Yeow WS, Lawson CM, Beilharz MW. Antiviral activities of individual murine IFN-alpha subtypes in vivo: intramuscular injection of IFN expression constructs reduces cytomegalovirus replication. J Immunol 1998; 160(6):2932-2939.

35. Halford WP, Veress LA, Gebhardt BM, Carr DJ. Innate and acquired immunity to herpes simplex virus type 1. Virology 1997; 236(2):328-337.

36. Harle P, Lauret E, Pitha PM, De Maeyer E, Carr DJ. Expression of human and macaque type I IFN transgenes interferes with HSV-1 replication at the transcriptional and translational levels: IFN-beta is more potent than IFN-alpha 2. Virology 2001; 290(2):237-248.

37. Noisakran S, Campbell IL, Carr DJ. Ectopic expression of DNA encoding IFN-alpha 1 in the cornea protects mice from herpes simplex virus type 1-induced encephalitis. J Immunol 1999; 162(7):41844190.

38. Noisakran SJ, Carr DJ. Therapeutic efficacy of DNA encoding IFN-alpha1 against corneal HSV-1 infection. Curr Eye Res 2000; 20(5):405-412.

39. Noisakran S, Carr DJ. Type I interferons and herpes simplex virus infection: a naked DNA approach as a therapeutic option? Immunol Res 2001; 24(1):1-11.

40. Noisakran S, Carr DJ. Topical application of the cornea post-infection with plasmid DNA encoding interferon-alpha1 but not recombinant interferonalphaA reduces herpes simplex virus type 1-induced mortality in mice. J Neuroimmunol 2001; 121(1-2):4958.
41. Harle P, Cull V, Agbaga MP, Silverman R, Williams BR, James C, et al. Differential effect of murine alpha/beta interferon transgenes on antagonization of herpes simplex virus type 1 replication. J Virol 2002; 76(13):6558-6567.

42. Donnelly JJ, Wahren B, Liu MA. DNA vaccines: progress and challenges. J Immunol 2005; 175(2):633639.

43. Bartlett EJ, Cull VS, Mowe EN, Mansfield JP, James CM. Optimization of Naked DNA Delivery for Interferon Subtype Immunotherapy in Cytomegalovirus Infection. Biol Proced Online 2003; 5:43-52.

44. Wang R, Doolan DL, Le TP, Hedstrom RC, Coonan $\mathrm{KM}$, Charoenvit $\mathrm{Y}$, et al. Induction of antigen-specific cytotoxic $\mathrm{T}$ lymphocytes in humans by a malaria DNA vaccine. Science 1998; 282(5388):476-480.

45. Tuting T, Austyn J, Storkus WJ, Falo LD Jr. The Immunology of DNA Vaccines. In: Lowrie DB, and Whalen, R. G., editor. DNA Vaccines: Methods and Protocols. Totawa, NJ: Humana Press Inc.; 2000. p. 37-64.

46. Mumper RJ, Ledebur HC Jr., Rolland AP, Tomlinson E. Controlled Plasmid Delivery and Gene Expression. In: Lowrie DB, and Whalen, R. G., editor. DNA Vaccines: Methods and Protocols. Totawa, NJ: Humana Press Inc.; 2000. p. 267-286.

47. Tan PH, Manunta M, Ardjomand N, Xue SA, Larkin DF, Haskard DO, et al. Antibody targeted gene transfer to endothelium. J Gene Med 2003; 5(4):311323.

48. Liang KW, Hoffman EP, Huang L. Targeted delivery of plasmid DNA to myogenic cells via transferrinconjugated peptide nucleic acid. Mol Ther 2000; 1(3):236-243.

49. Sambrook J, Fritsch EF, Maniatis T. Molecular Cloning: A Laboratory Manual. Cold Spring Harbor, NY: Cold Spring Harbor Laboratory Press; 1989. 


\section{PROTOCOLS}

Protocol for plasmid purification: A slightly modified protocol from that provided with the Quantum Prep Plasmid Maxiprep Kit (Bio-Rad Laboratories, Inc.) is listed below. Further details about plasmid purification have been described (49).

Re-suspension buffer: 50 mM d-glucose, 10 mM EDTA, 25 mM Tris $\mathrm{HCl}$ (pH 8.0), and 2 mg/ml lysozyme

Alkaline Lysis solution: $0.2 \mathrm{~N} \mathrm{NaOH}$ and 1\% SDS in sterile double distilled water

Wash buffer: $200 \mathrm{mM} \mathrm{NaCl}, 40 \mathrm{mM}$ Tris $\mathrm{HCl}, 4 \mathrm{mM}$ EDTA, adjust $\mathrm{pH}$ to 7.5, and add an equal volume of $100 \%$ ethanol

Neutralization buffer: $4 \mathrm{M}$ potassium-acetate $(\mathrm{pH} 4.8)$

Weigh $23.55 \mathrm{~g}$ potassium acetate. Add $66 \mathrm{ml}$ sterile double distilled water and $28.5 \mathrm{ml}$ glacial acetic acid. Titrate with approximately $1.5 \mathrm{ml}$ concentrated $\mathrm{HCl}$ to $\mathrm{pH} 4.8$. Adjust volume to $100 \mathrm{ml}$ with sterile double distilled water.

TE buffer: 10 mM Tris, 1 mM EDTA, pH 8.0

1. Grow bacteria containing each interferon transgene in $1 \mathrm{~L}$ of sterile Terrific broth (Bio 101 Systems), containing 50 $\mu \mathrm{g} / \mathrm{ml}$ kanamycin, by incubating overnight $(14-16 \mathrm{~h})$ at $37^{\circ} \mathrm{C}$ with shaking $(200 \mathrm{rpm})$.

2. Pellet bacteria by centrifugation ( 5 minutes at $5,000 \mathrm{~g}$ ) in $500 \mathrm{ml}$ sterile centrifuge bottles. Cells may be frozen at this point.

3. Thaw cells at room temperature. Re-suspend cells by adding $15 \mathrm{ml}$ cell re-suspension buffer containing DNase free RNase A ( 40 units $/ \mathrm{ml}$ ) to the pellet obtained from each $500 \mathrm{ml}$ of bacteria broth. Pipet up and down until the cells are completely re-suspended.

4. Add alkaline lysis buffer, containing a high concentration of anionic detergent $(23 \mathrm{ml} /$ pellet obtained from $500 \mathrm{ml}$ bacteria broth) to lyse cell membranes, denature chromosomal DNA and proteins, and release plasmid DNA into the supernatant. Make sure that SDS has not precipitated out of solution by making the solution fresh, or warm solution to $37^{\circ} \mathrm{C}$ prior to use to dissolve any visible precipitate. Mix by swirling the bottle. Avoid vortexing at any time in the procedure to avoid shearing DNA.

5. Neutralize by addition of $15 \mathrm{ml}$ neutralization solution to return the $\mathrm{pH}$ to normal and allow the 2 strands of plasmid DNA to return to the native state. Make sure there is no visible precipitate in the neutralization solution; if precipitate is visible, warm to $37^{\circ} \mathrm{C}$ prior to use.

6. Centrifuge at $10,000 \mathrm{~g} \times 30$ minutes to remove precipitated membrane, SDS, protein, and chromosomal DNA. Pour supernatant, containing plasmid DNA into a new centrifuge bottle. Centrifuge a second time at $10,000 \mathrm{~g} \times 10$ minutes to remove any remaining debris.

7. Bind plasmid DNA to a diatomaceous earth based DNA binding matrix by addition of $20 \mathrm{ml}$ re-suspended matrix to cleared lysate. Swirl gently for 30 seconds. Allow DNA to bind for 5 minutes, then centrifuge for 5 minutes at $3,000 \mathrm{~g}$ to pellet the matrix.

8. Wash matrix 4 times with one volume of wash buffer by centrifugation for $5 \mathrm{~min}$ at $4,000 \mathrm{rpm}$.

9. Elute DNA with $5 \mathrm{ml}$ sterile water $\times 2-3$ washes. Collect separate fractions from each wash. Typically one of the fractions will be more pure than the others.

10. Precipitate plasmid DNA by adding $1 / 18^{\text {th }}$ volume of $5 \mathrm{M} \mathrm{NaCl}$ and 2 volumes of cold $95-100 \%$ ethanol. Precipitate DNA overnight in the fridge.

11. Pellet DNA by centrifugation for 30 minutes at $10,000 \mathrm{~g}$.

12. Wash pellet by addition of $1 \mathrm{ml} 70 \%$ ethanol. Tap tube to re-suspend plasmid DNA. Decant into microcentrifuge tube and centrifuge at 10,000 rpm for 1 minute. Repeat 5 times.

13. Dry the pellet before re-suspending in TE buffer. 